\title{
The Effect of Aerobic Exercise on Different Symptoms of Depression: An Investigation of Psychological Mechanisms of Stress and Coping
}

\author{
Jafar Askari' ${ }^{1}$ Alireza Saberi-Kakhki ${ }^{2 *}$, Hamidreza Taheri², Seyyed Mojtaba Yassini ${ }^{3}$ \\ ${ }^{1}$ Department of Psychology, Imam Reza International University, Mashhad, Iran \\ ${ }^{2}$ Department of Motor Behavior, Faculty of Physical Education and Sport Sciences, Ferdowsi University of Mashhad, \\ Mashhad, Iran \\ ${ }^{3}$ Department of Psychiatry, Shahid Sadoughi University of Medical Sciences, Yazd, Iran \\ Email: jaskari@ssu.ac.ir, *askakhki@um.ac.ir, hamidtaheri@um.ac.ir, yassini@ssu.ac.ir
}

How to cite this paper: Askari, J., Saberi-Kakhki, A., Taheri, H. and Yassini, S.M. (2017) The Effect of Aerobic Exercise on Different Symptoms of Depression: An Investigation of Psychological Mechanisms of Stress and Coping. Open Journal of Medical Psychology, 6, 86-102.

https://doi.org/10.4236/ojmp.2017.62007

Received: January 19, 2017

Accepted: April 17, 2017

Published: April 20, 2017

Copyright $\odot 2017$ by authors and Scientific Research Publishing Inc. This work is licensed under the Creative Commons Attribution International License (CC BY 4.0).

http://creativecommons.org/licenses/by/4.0/

\begin{abstract}
Objectives: Considering the growing need for encouraging greater use of a variety of non-pharmacological methods in treating depression, the aim of this quasi experimental study was to examine the effect of aerobic exercise on triple categories of affective, cognitive and somatic symptoms of depression and to investigate its psychological mediators of perceived stress and coping strategies. Methods: Forty five female outpatients with major depressive disorder were divided into three groups including exercise + usual pharmacotherapy ( $n$ $=15)$, psychotherapy + usual pharmacotherapy $(n=14)$ and a control group receiving only usual pharmacotherapy $(n=16)$. The exercise used was included 36 one hour session (three sessions per week) with a low to medium intensity of $50 \%$ to $70 \%$ of the maximal heart rate. The psychotherapy used in this study was the behavioral activation treatment for depression revised. The Persian version of Beck Depression Inventory-II, Perceived Stress Scale and Coping Inventory for Stressful Situations were applied to assess the pre- and post-intervention depression, perceived stress, and coping strategies. Results: The findings indicated a significant decrease in the post-intervention scores of all three categories of affective, cognitive and somatic symptoms of depression and the perceived stress level in the adjunctive exercise and psychotherapy conditions compared with the control condition $(p=0.001)$, but there was no significant difference between the exercise and psychotherapy groups. In addition, no significant improvement was observed regarding the problem-centered, emotion-centered and avoidant-centered stress coping methods in the post-intervention scores of the exercise group compared with the control group. Conclusion: An adjunctive aerobic exercise program can be as effective as adding the psychotherapy to usual pharmacotherapy in further im-
\end{abstract}


provement in all three categories of depression symptoms especially mediated by reducing the amount of perceived stress, but not through any significant change in cognitive-behavioral coping strategies.

\section{Keywords}

Exercise and Physical Activity, Major Depressive Disorder,

Perceived Stress, Coping Strategies

\section{Introduction}

Major depressive disorder is considered as one of the most common psychological disorders around the world especially in women [1] and it is considered as a main public health problem [2]. The treatment of depression is multi-dimensional including medical treatments such as antidepressants, psychotherapy such as cognitive-behavioral therapy, or a combination of both [3]. Other studies have demonstrated that adding the cognitive-behavioral therapy to medical treatment causes a significant increase in the extent of improving depression [4]. However, only one-third of the patients affected with depression receive the sufficient and suitable treatment and about half of the patients experience recurrence after the treatment [5]. On the other hand, a change in life style mainly in the form of reduced physical activity is considered as one of the major health problems faced by the civil population [6]. In this respect, since many patients avoid using psychiatric drugs because of their side effects and the psychotherapy sessions because of its difficulties, many researchers and experts in the field of mental health are interested in evaluating other alternatives such as exercise and the physical activity as an adjunctive or independent method for treating depression [7].

Some of the studies carried out so far on the effect of adding aerobic exercise to the usual medical treatment protocol (the use of antidepressants and ECT) compared with only usual medical treatment showed a significant improvement in the rate of depression in the exercise groups [7] [8] [9] [10] [11]. According to Dunn, Trivedi, Kampert, Clark, \& Chambliss [12], an important point here is that the use of high intensity exercise $\left(75 \%-85 \% \mathrm{HR}_{\max }\right)$ is not plausible in patients with depression and does not agree with the public health recommendations. Nonetheless, there are some controversial issues regarding the efficacy of exercise on depression [13], and some studies do not support the effectiveness of exercise in decreasing depression [14] [15]. Thus, some researchers believe that it is rather impossible to draw a definitive conclusion on the positive effect of exercise and physical activity in improving depression in clinical cases and further research should be done to obtain more accurate evidence [5] [10]. In this regard, an important subject left, unaddressed in other studies is that which affective, cognitive, or somatic categories of depression symptoms are more affected by exercise and the physical activity. Accordingly, an objective of this study is to find out if exercise results in reduced depression, this reduction will be achieved mainly from the improvement in which groups of depression 
symptoms.

Additionally, the identification of the psychological mechanisms of exercise and physical activity involved in reducing depression is extremely important for mental health specialists. Based on current evidence, it appears that the perceived stress level is a determining factor in the relation between depression and physical activity [16]. In this regard, various clinical findings suggest that stress plays an important role in the etiology of depression [17]. On the other hand, it seems that physical activity can protect the individual against the detrimental consequences of stress and the related disorders including depression [18] [19]. Although, there are some contest and disagreement on the extent to which exercise can reduce the individual's sensitivity to the psychosocial stress [20]. In addition, there is no clear evidence indicating whether the psychological reactions of stress reduce parallel to the reduction in physiological reactions induced by exercise and present empirical evidence in this area is somewhat contradictory [21].

In addition to the effect of exercise on the level of perceived stress, the cognitive-behavioral responses of patients with depression for coping with stress and the effects of exercise on this variable are very important. However, until now the effect of physical exercise on changes in usage degree of triple methods of coping with stress (problem-centered, emotion-centered, and avoidant-centered) has not been addressed extensively. According to the theory by Folkman and Lazarus [22], adaptation methods and stress coping skills are divided into two categories: problem-centered coping (trying to solve the problem), and emotioncentered coping (trying to relieve the negative emotions induced by the problem). Later, Endler and Parker [23] added the avoidant coping to these two methods including keeping off the problem or involving one in other activities. Some recent studies revealed that depressed patients use harmful emotion-centered methods more frequently [24] [25]. Another study on the correlation between stress coping methods and depression in women demonstrated that depressed patients used the problem-centered method to a lesser degree compared with normal individuals while they used the emotion-centered method more frequently [26]. Additionally, some researchers postulate that exercise and physical activity can improve stress coping skills. It is asserted that exercise and physical activity, through promoting self-confidence, energy, and feelings of selfefficacy, helps the individual in two ways: First, stressful events cannot cause great harm to the person, and second, individuals with higher self-confidence and energy use the active problem-centered methods of stress coping more frequently [27]. Nevertheless, some researchers believe that a definitive conclusion in this regard could be achieved only after completion of sufficient and wider interventional experiments particularly on clinical populations [27]. Hence, regarding the very important role of stress and coping strategies with respect to depression and its treatment, investigating the fundamental role of these factors in the effect of exercise on depression is another objective of the present study. In addition, an important point in this study is the comparison of adjunctive aerobic exercise 
group with not only the usual pharmacotherapy (control) group, but also with the adjunctive psychotherapy group in terms of the degree of improvement in depression, stress, and coping strategies.

In summary, considering the growing need for encouraging greater use of a variety of non-pharmacological methods in treating depression, in the present study as one of the very few studies in this area on depressed outpatients, we aimed to answer the following two questions whether adding exercise to usual pharmacotherapy, as well as adding psychotherapy to usual pharmacotherapy, compared to the condition of usual pharmacotherapy alone can: (a) Make a significant decrease in all the three categories of affective, cognitive and somatic symptoms of depression or not? (b) Lead to a significant decrease in the level of perceived stress and a significant helpful change in using of cognitive-behavioral methods of problem-centered, emotion-centered and avoidant-centered coping with stress or not?

\section{Methods}

\subsection{Design and Participants}

This quasi experimental study was performed with two experimental and one control group. The participants were selected from the patients referring to the counseling clinic of a psychiatric hospital (Bahman Hospital in Yazd, Iran) from June to September 2014. This study was approved by the national ethics committee (IR.MUMS.REC.1395.6) and was registered as a clinical trial in Iranian registry of clinical trials (http://www.irct.ir) (Register Code:

IRCT2016082929598N1).

Research samples were selected from the patients who tended to voluntarily participate in the study using convenience-sampling method. The inclusion criteria were as follows: The women aged 20 - 50-year-old affected with moderate to severe major depressive disorder diagnosed by a psychiatrist via structured clinical interview based on the fifth version of the diagnostic and statistical manual of mental disorders (DSM-5) [28], and the minimum score of 20 on the Beck Depression Inventory-II [29], not being involved in other mental treatments (medical or psychological) and exercise programs during the study and declare her willingness to take part in the research and sign the informed consent statement. The exclusion criteria were as follows: Simultaneous affliction with other important mental disorders (such as schizophrenia, bipolar affective disorder and drug and alcohol abuse), having somatic problems affecting depression (such as hypothyroidism and diabetes mellitus) or restricts their physical activity (e.g., cardiovascular and musculoskeletal problems).

\subsection{Procedures}

The patients were allocated to one of the following groups: Aerobic exercise + usual pharmacotherapy group, a comparison group of psychotherapy + usual pharmacotherapy and a control group of usual pharmacotherapy per se. During the enrollment, the first and second 18 eligible patients allocated to aerobic exer- 
cise and psychotherapy interventions, respectively. The last third group, containing another 18 eligible patients, underwent only usual pharmacotherapy. In order to enroll the participants after referral by psychiatrist, they must complete demographic data form and the research questionnaires including depression and stress pre-tests at the psychiatric clinic in the form of face to face interview. Resting heart rate was also recorded after a few minutes of resting in sitting position. Enrollment of the patients in each group usually lasted between $2-4$ weeks. Therapeutic interventions were started after finishing the enrollments and performing the pre-tests. Post-tests were also conducted at a time within the first day immediately after the end of interventions. To enhance the patients' cooperation during the study, researchers paid all costs and expenses incurred (e.g., the costs of transportation, gym and laboratory tests).

\subsubsection{Aerobic Exercise Program}

Exercise group used 60 min of group aerobic exercise accompanied by rhythmic music with a schedule of three sessions per week for three months with an intensity of low to medium, accounting for $50 \%-70 \%$ of the maximal heart rate. According to various ages of the participants ranging from 20 - 50 years, the intensity of physical activity varied from at least $87.20 \mathrm{bpm}\left(50 \% \mathrm{HR}_{\max }\right)$ in the oldest patient (48 years old) to $135.80 \mathrm{bpm}\left(70 \% \mathrm{HR}_{\max }\right.$ ) in the youngest patient (20 years old). During each session the total time and intensity of exercise were calculated and controlled by one of the trained research staff. The exercise was performed in a gym salon of $90 \mathrm{~m}^{2}$ under the supervision of a trained couch and without presence of other people. The time of performing the exercise was scheduled to be between 18 - 19 p.m. in the summer at a temperature of about $20^{\circ} \mathrm{C}$. Due to the national yearly holidays, two exercise sessions were cancelled. The aerobic exercise used in this study was performed as follows: (a) About $10-15$ min gentle stretching movements for warming up the body as advised by other studies [30]. (b) The main body of exercise included about 30 - 40 min of more rapid movements such as various movements of hands, feet, and trunk in the sitting and standing positions such as pedaling, forward, backward and lateral movements, bending and straitening forward, left and right, sit-ups, and jumping or leaping movements. (c) About 10 - 15 min of gentle stretching movements for cooling down as advised by other studies [31]. During the study, the patients in this group were receiving usual pharmacotherapy in addition to participation in exercise sessions based on the orders of psychiatrist.

\subsubsection{Psychotherapy}

Besides usual medication the patients of psychotherapy group were treated in specialized clinic by a trained clinical psychologist using the modified manual of behavioral activation treatment for depression-revised (BATD-R) [32]. According to Lejuez et al. [32] this treatment is commonly performed in 12 sessions. In this study, the psychotherapy sessions were conducted once every week for 3 months (12 sessions overall). These sessions were held with the patients at the clinic or on the phone in some weeks. The initial sessions usually lasts one hour 
(Sessions 1 - 3). Gradually, as the patients become entirely accustomed to the method, the duration of each session decreases to less than 15 - 30 minutes. Exceptionally, behavioral activation through encouraging the patients to perform physical activities was avoided in this study.

\subsubsection{Usual Pharmacotherapy}

During the study, the members of this group were just taking prescribed medications and they did not participate in ECT, psychotherapy or any kind of physical activities. The medications used by the participants were included tricyclic antidepressants (clomipramine, imipramine and trimipramine), selective serotonin reuptake inhibitors (SSRIs) (fluoxetine, citalopram and sertraline), norepinephrine-dopamine reuptake inhibitors (NDRIs) (bupropion), benzodiazepines (alprazolam and chlordiazepoxide) and other anti-anxiety drugs and tranquilizers (propranolol, trifluoperazine and perphenazine). The type and dosage of medications for each patient were determined by the psychiatrist.

\subsection{Measures}

\subsubsection{Intensity of Physical Activity and Resting Heart Rate}

$\mathrm{HR}_{\text {max }}$ measured by the digital heart rate monitor Beurer model PM110 made in Germany was used to determine the intensity of physical activity. $\mathrm{HR}_{\max }$ is commonly used as an index for prescribing exercise intensity in rehabilitation programs [33]. The formula: "208 - $0.7 \times$ age" [34] was used here in identifying physical activity intensity. $\mathrm{HR}_{\max }$ divides intensity of physical activities to the three low $\left(50 \%-65 \% \mathrm{HR}_{\max }\right)$, medium $\left(65 \%-75 \% \mathrm{HR}_{\max }\right)$, and high $(75 \%-85 \%$ $\mathrm{HR}_{\max }$ ) levels [35]. Resting heart rate was also measured by the monitor.

\subsubsection{Depression}

The depression scores before and after interventions were estimated using the Persian version of Beck Depression Inventory-II (BDI-II) [29]. This inventory has 21 sections and each section is scored on a scale of 0 - 3. Accordingly, the total score of each individual varies between 0 - 63. The scores between $0-13$ indicates minimal depression, 14 - 19 mild to moderate depression, 20 - 28 moderate to severe depression and higher than 29 severe depression [29]. The BDI-II is one of the most frequently used instruments for measuring the severity of depression and it has a high reliability and acceptable concurrent, content, and structural validity [36]. The reliability and validity of the Persian version is reported to be optimal in previous studies [37].

\subsubsection{Stress}

To measure the rate of stress, the Persian version of the Perceived Stress Scale (PSS) [38] was used. It has 10 items, scored on a 5-point Likert scale from 0 (never) to 4 (most of the time). Items $4,5,7$ and 8 are scored in reverse. Consequently, the total score of 0 - 40 will be obtained. The scores $0-7$ are classified as very low stress, 8 - 11 low, 12 - 15 average, 16 - 20 high and above 21 very high [38]. The reliability and validity of the original version of this questionnaire [39] 
and those of the Persian version [40] are acceptable.

\subsubsection{Coping}

The Persian version of the Coping Inventory for Stressful Situations (CISS) [41] was applied to assess the stress coping methods. This inventory consists of 48 items measuring the three methods of coping with stress including problemcentered (16 items), emotion-centered (16 items), and avoidant-centered method (16 items). The answer to each question is based on a five-point Likert scale includes from 1 (never) to 5 (very high) and the total score of each section varies from 16 to 80 . The validity and reliability of the original version [42] and those of the Persian version [43] are acceptable.

\subsection{Sample Size}

Based on a two sided confidence interval of $95 \%$, test power of $80 \%$, standard deviation of 11 with regard to BDI-II scores from some former studies, and in order to attain a significant difference based on a minimum difference of 12 between group mean scores, sample size was chosen to be three groups of 15. A total of 3 individuals (20\%) were then added to each group in order to compensate for subject loss. As such, the final number of individuals in each group was 18 .

\subsection{Statistical Analysis}

Data were analyzed using the SPSS-20 software. Regarding the normal distribution of the data based on Klomogrov-Smironov test $(p>0.05)$, the parametric statistics of one-way ANOVA, ANCOVA, MANCOVA, Bonfereni post hoc test and partial eta squared were used as appropriated. One-way ANOVA was used to compare the pre-test scores of demographic characteristics and clinical variables (depression, perceived stress, cortisol secretion level), and the doses of consumed medications of the three study groups. ANCOVA, MANCOVA, and Bonferroni test in addition to partial eta squared was also used to check the observed differences between the pre- and post-test scores of clinical variables, and calculate effect size, respectively.

\section{Results}

A total of 105 patients were referred to participate in the study. Of these patients, $51(48.5 \%)$ excluded from the study and 54 were non-randomly allocated to the aerobic exercise $(n=18)$, psychotherapy $(n=18)$ and the control group $(n=18)$. Among 54 patients who were invited to participate in the study, 9 (16.6\%) patients dropped out in the early stages of the study (three, four and two in the exercise, psychotherapy and control groups, respectively). They dropped out because of lack of interest in exercise and lack of required physical preparation in the exercise group, spouse disagreement and inability for weekly referral in the psychotherapy group and not using medications because of their complications and side effects in the control group. Therefore, the research data were analyzed using 15, 14 and 16 patients in the exercise, psychotherapy and control groups, respectively. 


\subsection{Baseline Findings}

The total means (standard deviations) of age, education, height, weight, and resting heart rates of the women of the three groups were 33.02 (7.11) years (age), 11.15 (3.76) years (education), $165.08(5.63) \mathrm{cm}, 73.84(7.38) \mathrm{kg}$ and 84.75 (6.19) bpm, respectively. Before the intervention, the total means (standard deviations) of using tests in all the three groups were as follows: BDI-II: total score: 39.51 (9.19), affective symptoms: 14.04 (3.86), cognitive symptoms: 15.95 (4.61), and somatic symptoms: 9.53 (2.57); PSS-10: 28.08 (6.76); CISS: problem-centered method: 37.17 (14.56), emotion-centered method: 60.15 (11.04) and avoidantcentered method: 29.73 (8.94). Based on a one-way between groups ANOVA, there was no statistically significant difference among the three groups regarding all baselines demographic and clinical characteristics (see Table 1). According to baseline findings, the participants of the study were affected with moderate to severe depression, very high degrees of stress and greater use of emotion-centered coping compared to problem-centered and avoidant-centered methods. There was also no significant difference between the average doses of medications taken by the groups of exercise $(M=149.53, S D=85.83)$, psychotherapy $(M=129.78, S D=77.32)$, and control $(M=154.56, S D=84.38) \mathrm{mg}, F(2,42)=$ $0.36, p=0.696)$. In addition, the mean duration of affliction with depression in all of the participants was 11.11 (9.05) months.

Table 1. Baseline demographic and clinical characteristics of the participants.

\begin{tabular}{|c|c|c|c|c|c|}
\hline Measures & $\begin{array}{c}\text { 1-exercise }(n=15) \\
M(S D)\end{array}$ & $\begin{array}{c}\text { 2-Psychotherapy }(n=14) \\
M(S D)\end{array}$ & $\begin{array}{c}\text { 3-Control }(n=16) \\
M(S D)\end{array}$ & $\begin{array}{c}F \\
(2,42)\end{array}$ & $p$ \\
\hline Age (years) & $34.40(8.33)$ & $31.21(5.89)$ & $33.31(6.95)$ & 0.73 & 0.775 \\
\hline Education (years) & $10(4)$ & $12.42(3.67)$ & $11.12(3.48)$ & 1.54 & 0.435 \\
\hline Height $(\mathrm{cm})$ & $163.06(7.37)$ & $165.85(5.06)$ & $166.31(3.71)$ & 1.50 & 0.233 \\
\hline Weight (kg) & $76.33(8.48)$ & $71.78(5.78)$ & $73.31(7.31)$ & 1.46 & 0.242 \\
\hline Rest heart rate (bpm) & $84.60(5.06)$ & $85.28(6.73)$ & $84.43(6.99)$ & 0.07 & 0.929 \\
\hline BDI-II (total score) & $36.33(9.67)$ & $41.35(6.12)$ & $40.87(10.62)$ & 1.37 & 0.264 \\
\hline BDI-II (affective symptoms) & $12.73(3.75)$ & $15.14(3.25)$ & $14.31(4.31)$ & 1.49 & 0.235 \\
\hline BDI-II (cognitive symptoms) & $14.33(5.36)$ & $17.07(2.78)$ & $16.50(4.97)$ & 1.47 & 0.240 \\
\hline BDI-II (somatic symptoms) & $9.33(2.12)$ & $9.14(2.79)$ & $10.06(2.81)$ & 0.53 & 0.590 \\
\hline PSS-10 & $27.93(7.04)$ & $25.35(5.03)$ & $30.62(7.22)$ & 2.41 & 0.102 \\
\hline CISS (P-CC) & $39.26(14.55)$ & $34.92(13.56)$ & $37.18(15.98)$ & 0.31 & 0.734 \\
\hline CISS (E-CC) & $59.93(10.11)$ & $64(5.27)$ & $57(14.61)$ & 1.54 & 0.226 \\
\hline CISS (ACC) & $29.66(8.99)$ & $30.50(8.68)$ & $29.12(9.63)$ & 0.08 & 0.918 \\
\hline
\end{tabular}

Note: bpm = beats per minute; BDI-II = Beck Depression Inventory-II; PSS = Perceived Stress Scale; CISS = Coping Inventory for Stressful Situations; P-CC $=$ Problem-Centered Coping; E-CC $=$ Emotion-Centered Coping; ACC = Avoidant-Centered Coping. 


\subsection{Exercise Effects on Depression}

Post-tests comparison of the total depression scores using an ANCOVA demonstrated a significant difference in the three groups $(F(2,42)=17.77, p=0.001$, $\left.\eta_{p}^{2}=046\right)$ (see Table 2). Post-hoc comparisons using the Bonferroni test indicated that the mean scores for exercise $(M=18.46, S D=11.64)$ and psychotherapy $(M=17.92, S D=5.77)$ conditions were significantly different from the control condition $(M=32.93, S D=10.50, p=0.001)$. Based on a MANCOVA this difference was also observed in all the triple affective $(F(2,42)=17.09, p=$ $\left.0.001, \eta_{p}^{2}=0.47\right)$, cognitive $\left(F(2,42)=10.44, p=0.001, \eta_{p}^{2}=0.35\right)$, and somatic $\left(F(2,42)=14.61, p=0.001, \eta_{p}^{2}=0.43\right)$ subscales at BDI-II. These results suggest that participating in an exercise program truly has a remarkable positive effect on further improvement of depression. More importantly, no significant difference was found between the exercise and psychotherapy groups regarding the post-intervention decrease in the amount of depression scores.

\subsection{Exercise Effects on Stress and Coping}

Post-tests comparison of the three groups using an ANCOVA and post hoc Bonferroni test indicated a significantly reduced perceived stress $(F(2,42)=$ 14.31, $p=0.001, \eta_{p}^{2}=0.41$ ), in both exercise and psychotherapy conditions compared with the control condition (see Table 2). These results suggest that participating in the exercise program can lead to a considerable reduction in the amount of perceived stress. But importantly, similar to the depression variable, no significant difference was found between the exercise and psychotherapy groups regarding the post-intervention decrease in the amount of perceived stress.

With respect to the coping strategies in post-intervention scores, the use of problem-centered method was significantly greater only in the psychotherapy group compared with the exercise and control groups $(F(2,42)=11.66, p=$ $\left.0.001, \eta_{p}^{2}=0.37\right)$. There was also no significant difference among the groups

Table 2. Post-intervention comparison of the measured clinical characteristics

\begin{tabular}{|c|c|c|c|c|c|c|c|}
\hline Measures & $\begin{array}{c}\text { 1-Exercise }(n=15) \\
M(S D)\end{array}$ & $\begin{array}{c}\text { 2-Psychotherapy }(n=14) \\
M(S D)\end{array}$ & $\begin{array}{c}\text { 3-Control }(n=16) \\
M(S D)\end{array}$ & $\begin{array}{c}F \\
(2,42)\end{array}$ & $p$ & $\eta_{\mathrm{p}}^{2}$ & Bonfereni \\
\hline BDI-II (total score) & $18.46(11.64)$ & $17.92(5.77)$ & $32.93(10.50)$ & 17.77 & 0.001 & 0.46 & $1,2<3$ \\
\hline BDI-II (affective symptoms) & $6.33(3.77)$ & $6.14(2.03)$ & $11.68(4.34)$ & 17.09 & 0.001 & 0.47 & $1,2<3$ \\
\hline BDI-II (cognitive symptoms) & $7.73(6.09)$ & $7.35(2.73)$ & $13.31(4.52)$ & 10.44 & 0.001 & 0.35 & $1,2<3$ \\
\hline BDI-II (somatic symptoms) & $4.40(2.55)$ & $4.35(1.78)$ & $7.93(2.51)$ & 14.61 & 0.001 & 0.43 & $1,2<3$ \\
\hline PSS-10 & $16.60(6.68)$ & $15.50(4.71)$ & $27.06(6.27)$ & 14.31 & 0.001 & 0.41 & $1,2<3$ \\
\hline CISS (P-CC) & $47.26(15.34)$ & $54.14(10.87)$ & $40.87(13)$ & 11.66 & 0.001 & 0.37 & $2>1,3$ \\
\hline CISS (E-CC) & $47.53(8.22)$ & $49.42(4.71)$ & $54.37(13.64)$ & 2.27 & 0.116 & 0.10 & - \\
\hline CISS (ACC) & $31.46(8.72)$ & $24.71(8.97)$ & $30.50(10.26)$ & 12.45 & 0.001 & 0.39 & $2<1,3$ \\
\hline
\end{tabular}

Note: BDI-II = Beck Depression Inventory-II; PSS = Perceived Stress Scale; CISS = Coping Inventory for Stressful Situations; P-CC = Problem-Centered Coping; ECC $=$ Emotion-Centered Coping; ACC $=$ Avoidant-Centered Coping. 
after the intervention with respect to the emotion-centered method $(F(2,42)=$ 2.27, $p=0.116, \eta_{p}^{2}=0.10$ ), and the use of avoidant-centered method significantly reduced in the psychotherapy group compared with the exercise and control groups $\left(F(2,42)=12.45, p=0.001, \eta_{p}^{2}=0.39\right)$. This part of the results indicated that participating in the exercise program fails to have a significant impact on changing various cognitive-behavioral strategies of coping.

\section{Discussion}

This study aimed to assess the efficacy of aerobic exercise as an adjunctive treatment to pharmacotherapy compared with adjunctive psychotherapy and pharmacotherapy alone on triple categories of affective, cognitive and somatic symptoms of depression and to investigate its psychological mediators of perceived stress and coping strategies.

On the basis of our findings a comparison of groups' post-tests demonstrated that adding aerobic exercise to pharmacotherapy significantly improved all three categories of affective, cognitive and somatic symptoms of depression in this group compared with the control group. This is consistent with the findings by other researchers [7] [8] [11] [44]. Predicated on some other studies as to the effect of exercise on depression, the results indicate that, for example, affective improvement can occur by increasing the amount of serotonin secretion [45], cognitive promotion can be achieved through increasing self-esteem [46], and more healthy somatic condition can occur via better sleep quality [47]. Comparison of the post-tests of the two exercise and psychotherapy groups also indicated that aerobic exercise can improve all the triple symptoms of depression in this group similar to psychotherapy one and none of these methods is superior to the other. This result also is consistent with the findings by Mead et al. [48].

Considering the effect of exercise and physical activity on the affective, cognitive and somatic dimensions of depression, an important issue is the underlying related mechanisms including the role of the changes in the amount of perceived stress and the use of various methods of stress coping. Regarding the role of perceived stress, the findings revealed that the rate of reduction in stress after intervention was significantly greater in the exercise condition compared with the control one, though this difference was not significant in the exercise compared with the psychotherapy condition. This finding indicates that adding exercise to the usual pharmacotherapy can improve depression symptoms particularly through decreasing stress. It is believed that stress affects patients with major depression differently than normal individuals so that a minor stress is sufficient for a new depression attack [49]. This finding supports the kindling-sensitization hypothesis stating that the repetition of stressful incidents gradually makes the brain sensitive and vulnerable to stress and leading to subsequent depression attacks [49]. It is asserted that this happens due to the sensitization of the HPA axis, specifically the increased sensitivity of mineralocorticoid receptors towards negative feedback induced by stress [50]. At the psychological level, some studies indicate that depressed patients suffer from more mood deterioration 
when they face stress compared with normal individuals and they also generally perceive life events more stressful than normal individuals [51]. On the other hand, some recent studies suggest that the physically more active individuals acquire more resistance and adaptation against not only the consequences of physical stresses, but also against the psychosocial stresses of the daily living [52]. According to the cross-stressor adaptation hypothesis [53], repeated challenges of the physiological system during physical activities creates a kind of resistance and adaptation so that the sensitivity of the system to other stressors of the same type (various physical activities) and even other psychosocial stressors (like familial, occupational, educational, financial and etc.) gradually decreases. In this regard a study that was conducted to see the efficacy of a 20 -week aerobic exercise program on improving the students' emotional reactions to stress induced by daily life events indicated that the participants in the exercise group showed milder emotional reactions to final exam stress compared with the control group [54].

Furthermore, to psychologically explain the anti-stress consequences of exercise on depression, it has been emphasized that physical activity reduced stress and emotional reactions through strengthening the individual against mental rumination or repetitious reviewing of negative thoughts [55]. According to response style theory [56] depressed patients may usually show two types of responses against their negative painful thoughts: Some begin to ruminate these negative painful thoughts while others, on the contrary, try to distract their attention towards daily living activities or even towards pleasant thoughts. According to Nolen-Hoeksema [57] women are more likely to become depressed due to excessive rumination of stressful life events. Many researchers consider chronic and severe rumination as an important factor in mental pathology [58] and the rate of incidence of new depression attacks could be predicted on the basis of this factor [59]. Accordingly, the distraction strategy as opposed to mental rumination can be introduced as another possible explanation for justifying the anti-stress and anti-depression effects of exercise and physical activity.

Additionally, to justify the positive effects of group exercise on mental and emotional health, it seems that the role of social interaction is of utmost importance. Social relationships and interactions are usually divided into three groups of social support, social network, and social connectedness [60]. It is argued that social relationships including wider social support, greater social network, and deeper social connectedness may reduce the incidence of psychological disorders especially depression by preventing the deleterious effects of stress [61]. Furthermore, it is also asserted that the positive feedback due to social interactions created by participating in exercise activities leads to decreased cortisol secretion particularly in women [62]. Hence, another important mechanism of the effect of exercise on stress and mental health is manifested as helping to create and increase social relations and the emotional related benefits [63] [64].

With respect to various stress coping methods, the results of the baseline measurements indicated that all the participants used the emotion-centered me- 
thod more frequently than the other two methods. This is consistent with previous studies [24] [25] [26]. Based on post-test scores, the physical activity program in the exercise group did not lead to any significant improvement in stress coping methods after intervention compared with the control group. This is not consistent with the findings of some studies such as Wijndaele et al. [27]. A possible explanation for this inconsistency is that in order for exercise to exert its positive effects on the cognitive, emotional, and behavioral characteristics, specially the stress coping strategies, there is a need for a longer time. This can be studied in cross-sectional studies (such as Wijndaele et al.) since the researcher can investigate the effect of many years of physical activity on mental and behavioral properties. Moreover, many researchers believe that improving stress coping strategies is basically possible via psychological training [65]. It seems that urging and training the patients to use more effective stress coping skills are usually indispensible components of the cognitive-behavioral interventions [66]. Consequently, although it appears that short-term programs of exercise and physical activity may induce a considerable effect on improving mood and temper, yet, they cannot create any significant improvement in problem-centered, emotioncentered and avoidant-centered methods of stress coping compared with pharmacotherapy or psychotherapy.

\section{Conclusion}

In conclusion, our findings suggest that in clinical settings similar to psychotherapy methods, aerobic exercise can be used as an adjunct (or independent) treatment to improve all three categories of affective, cognitive and somatic symptoms of depression especially mediated by reducing the amount of the perceived stress level, but not through any changes in cognitive-behavioral stress coping strategies.

\section{Acknowledgements}

Thanks to the head and personnel of Bahman Psychiatric Hospital in Yazd, Iran for their support.

\section{Conflict of Interest}

The authors declare that they have no conflict of interest.

\section{References}

[1] Kwasky, A.N. and Groh, C.J. (2014) Vitamin D, Depression and Coping Self-Efficacy in Young Women: Longitudinal Study. Archives of Psychiatric Nursing, 28, 362-367. https://doi.org/10.1016/j.apnu.2014.08.010

[2] Zeng, Q., Xu, Y. and Wang, W.C. (2013) Quality of Life in Outpatients with Depression in China. Journal of Affective Disorders, 150, 513-521. https://doi.org/10.1016/j.jad.2013.04.052

[3] Stubbs, B., Vancampfort, D., Rosenbaum, S., Ward, P.B., Richards, J., Soundy, A., Veronese, N., Solmi, M. and Schuch, F.B. (2016) Dropout from Exercise Randomized Controlled Trials among People with Depression: A Meta-Analysis and Meta 
Regression. Journal of Affective Disorders, 190, 457-466.

https://doi.org/10.1016/j.jad.2015.10.019

[4] Button, K.S., Turner, N., Campbell, J., Kessler, D., Kuyken, W., Lewis, G., Peters, T.J., Thomas, L. and Wiles, N. (2015) Moderators of Response to Cognitive Behavioural Therapy as an Adjunct to Pharmacotherapy for Treatment-Resistant Depression in Primary Care. Journal of Affective Disorders, 174, 272-280.

https://doi.org/10.1016/j.jad.2014.11.057

[5] Schuch, F.B., Dunn, A.L., Kanitz, A.C., Delevatti, R.S. and Fleck, M.P. (2016) Moderators of Response in Exercise Treatment for Depression: A Systematic Review. Journal of Affective Disorders, 195, 40-49. https://doi.org/10.1016/j.jad.2016.01.014

[6] Jacka, F.N., Pasco, J.A., Williams, L.J., Leslie, E.R., Dodd, S., Nicholson, G.C., Kotowicz, M.A. and Berk, M. (2011) Lower Levels of Physical Activity in Childhood Asso-ciated with Adult Depression. Journal of Science and Medicine in Sport, 14, 222 226. https://doi.org/10.1016/j.jsams.2010.10.458

[7] Schuch, F.B., Vasconcelos-Moreno, M.P., Borowsky, C., Zimmermann, A.B., Rocha, N.S. and Fleck, M.P. (2015) Exercise and Severe Major Depression: Effect on Symptom Severity and Quality of Life at Discharge in an Inpatient Cohort. Journal of Psychiatric Research, 61, 25-32. https://doi.org/10.1016/j.jpsychires.2014.11.005

[8] Atlantis, E., Chow, C.M., Kirby, A. and Fiatarone, S.M. (2004) An Effective Exercise-Based Intervention for Improving Mental Health and Quality of Life Measures: A Randomized Controlled Trial. Preventive Medicine, 39, 424-434.

[9] Kerling, A., Tegtbur, U., Gützlaff, E., Kück, M., Borchert, L., Ates, Z., von Bohlen, A., Frieling, H., Hüper, K., Hartung, D., Schweiger, U. and Kahl, K.G. (2015) Effects of Adjunctive Exercise on Physiological and Psychological Parameters in Depression: A Randomized Pilot Trial. Journal of Affective Disorders, 177, 1-6. https://doi.org/10.1016/j.jad.2015.01.006

[10] Mota-Pereira, J., Silverio, J., Carvalho, S., Ribeiro, J.C., Fonte, D. and Ramos, J. (2011) Moderate Exercise Improves Depression Parameters in Treatment-Resistant Patients with Major Depressive Disorder. Journal of Psychiatric Research, 45, 1005 1011. https://doi.org/10.1016/j.jpsychires.2011.02.005

[11] Schuch, F.B., Vasconcelos-Moreno, M.P., Borowsky, C. and Fleck, M.P. (2011) Exercise and Severe Depression: Preliminary Results of an Add-On Study. Journal of Affective Disorders, 133, 615-618.

[12] Dunn, A.L., Trivedi, M.H., Kampert, J.B., Clark, C.G. and Chambliss, H.O. (2002) The DOSE Study: A Clinical Trial to Examine Efficacy and Dose Response of Exercise as Treatment for Depression. Controlled Clinical Trials, 23, 584-603.

[13] Danielsson, L., Papoulias, I., Petersson, E.L., Carlsson, J. and Waern, M. (2014) Exercise or Basic Body Awareness Therapy as Add-On Treatment for Major Depression: A Controlled Study. Journal of Affective Disorders, 168, 98-106. https://doi.org/10.1016/j.jad.2014.06.049

[14] De Moor, M.H.M., Boomsma, D.I., Stubbe, J.H., Willemsen, G. and De Geus, E.J.C. (2008) Testing Causality in the Association between Regular Exercise and Symptoms of Anxiety and Depression. Archives of General Psychiatry, 65, 897-905. https://doi.org/10.1001/archpsyc.65.8.897

[15] Kerse, N., Hayman, K.J., Moyes, S.A., Peri, K., Robinson, E., Dowell, A., Kolt, G.S., Elley, C.R., Hatcher, S., Kiata, L., Wiles, J., Keeling, S., Parsons, J. and Arroll, B. (2010) Home-Based Activity Program for Older People with Depressive Symptoms: DeLLITE-A Randomized Controlled Trial. Annals of Family Medicine, 8, 214-223. https://doi.org/10.1370/afm.1093

[16] Rimmele, U., Seiler, R., Marti, B., Wirtz, P.H., Ehlert, U. and Heinrichs, M. (2009) 
The Level of Physical Activity Affects Adrenal and Cardiovascular Reactivity to Psychosocial Stress. Psychoneuroendocrinology, 34, 190-198. https://doi.org/10.1016/j.psyneuen.2008.08.023

[17] Lange, C., Zschucke, E., Ising, M., Uhr, M., Bermpohl, F. and Adli, M. (2013) Evidence for a Normal HPA Axis Response to Psychosocial Stress in Patients Remitted from Depression. Psychoneuroendocrinology, 38, 2729-2736. https://doi.org/10.1016/j.psyneuen.2013.06.033

[18] Motl, R.W., Birnbaum, A.S., Kubik, M.Y. and Dishman, R.K. (2004) Naturally Occurring Changes in Physical Activity Are Inversely Related to Depressive Symptoms during Early Adolescence. Psychosomatic Medicine, 66, 336-342.

[19] Nabkasorn, C., Miyai, N., Sootmongkol, A., Junprasert, S., Yamamoto, H., Arita, M. and Miyashita, K. (2005) Effects of Physical Exercise on Depression, Neuroendocrine Stress Hormones and Physiological Fitness in Adolescent Females with Depressive Symptoms. The European Journal of Public Health, 16, 179-184.

https://doi.org/10.1093/eurpub/cki159

[20] Rimmele, U., Zellweger, B.C., Marti, B., Seiler, R., Mohiyeddini, C., Ehlert, U. and Heinrichs, M. (2007) Trained Men Show Lower Cortisol, Heart Rate and Psychological Responses to Psychosocial Stress Compared with Untrained Men. Psychoneuroendocrinology, 32, 627-635. https://doi.org/10.1016/j.psyneuen.2007.04.005

[21] Klaperski, S., von Dawans, B., Heinrichs, M. and Fuchs, R. (2013) Does the Level of Physical Exercise Affect Physiological and Psychological Responses to Psychosocial Stress in Women? Psychology of Sport and Exercise, 14, 266-274.

[22] Folkman, S. and Lazarus, R.S. (1985) If It Changes It Must Be a Process: Study of Emotion and Coping during Three Stages of a College Examination. Journal of Personality and Social Psychology, 48, 150-170. https://doi.org/10.1037/0022-3514.48.1.150

[23] Endler, N.S. and Parker, J.D.A. (1990) Multidimensional Analysis of Coping: A Critical Evaluation. Journal of Personality and Social Psychology, 58, 844-854. https://doi.org/10.1037/0022-3514.58.5.844

[24] Horwitz, A.G., Hill, R.M. and King, C.A. (2011) Specific Coping Behaviors in Relation to Adolescent Depression and Suicidal Ideation. Journal of Adolescence, 34, 1077-1085. https://doi.org/10.1016/j.adolescence.2010.10.004

[25] Sugawara, N., Yasui-Furukori, N., Sasaki, G., Tanaka, O., Umeda, T., Takahashi, I., Iwane, K., Matsuzaka, M., Kaneko, S. and Nakaji, S. (2012) Coping Behaviors in Relation to Depressive Symptoms and Suicidal Ideation among Middle-Aged Workers in Japan. Journal of Affective Disorders, 142, 264-268. https://doi.org/10.1016/j.jad.2012.05.011

[26] Hori, H., Teraishi, T., Ota, M., Hattori, K., Matsuo, J., Kinoshita, Y., Ishida, I., Nagashima, A., Koga, N., Higuchi, T. and Kunugi, H. (2014) Psychological Coping in Depressed Outpatients: Association with Cortisol Response to the Combined Dexamethasone/CRH Test. Journal of Affective Disorders, 152-154, 441-447. https://doi.org/10.1016/j.jad.2013.10.013

[27] Wijndaele, K., Matton, L., Duvigneaud, N., Lefevre, J., De Bourdeaudhuij, I., Duquet, W. and Philippaerts, R.M. (2007) Association between Leisure Time Physical Activity and Stress, Social Support and Coping: A Cluster-Analytical Approach. Psychology of Sport and Exercise, 8, 425-440.

[28] American Psychiatric Association (2013) Diagnostic and Statistical Manual of Mental Disorders (DSM-V). 5th Edition, American Psychiatric Publishing, Arlington, VA.

[29] Beck, A.T., Steer, R.A. and Brown, G.K. (1996) BDI-II, Beck Depression Inventory: 
Manual. 2nd Edition, Harcourt Brace, Boston.

[30] Law, R.Y.W. and Herbert, R.D. (2007) Warm-Up Reduces Delayed-Onset Muscle Sore-ness but Cool-Down Does Not: A Randomised Controlled Trial. Australian Jour-=nal of Physiotherapy, 53, 91-95.

[31] Malliou, P., Rokka, S., Beneka, A., Mavridis, G. and Godolias, G. (2007) Reducing Risk of Injury Due to Warm Up and Cool Down in Dance Aerobic Instructors. Journal of Back \& Musculoskeletal Rehabilitation, 20, 29-35. https://doi.org/10.3233/BMR-2007-20105

[32] Lejuez, C.W., Hopko, D.R., Acierno, R., Daughters, S.B. and Pagoto, S.L. (2011) Ten Year Revision of the Brief Behavioral Activation Treatment for Depression: Revised Treatment Manual. Behavioral Modification, 35, 111-161. https://doi.org/10.1177/0145445510390929

[33] American College of Sports Medicine (2000) ACSM's Guidelines for Exercise Testing and Prescription. 6th Edition, Lippincott Williams \& Wilkins, Baltimore, MD.

[34] Tanaka, H., Monahan, K.D. and Seals, D.R. (2001) Age-Predicted Maximal Heart Rate Revisited. Journal of the American College of Cardiology, 37, 153-156.

[35] American College of Sports Medicine (2010) ACSM's Guidelines for Exercise Testing and Prescription. 8th Edition, Wolters Kluwer/Lippincott Williams \& Wilkins, Philadelphia.

[36] Wang, Y.P. and Gorenstein, C. (2013) Psychometric Properties of the Beck Depression Inventory-II: A Comprehensive Review. Revista Brasileira de Psiquiatria, 35, 416-431. https://doi.org/10.1590/1516-4446-2012-1048

[37] Ghassemzadeh, H., Mojtabai, R., Karamghadiri, N. and Ebrahimkhani, N. (2005) Psychometric Properties of a Persian-Language Version of the Beck Depression Inventory-Second Edition: BDI-2-Persian. Depression and Anxiety, 21, 185-192. https://doi.org/10.1002/da.20070

[38] Cohen, S., Kamarck, T. and Mermelstein, R.A. (1983) A Global Measure of Perceived Stress. Journal of Health and Social Behavior, 24, 385-396. https://doi.org/10.2307/2136404

[39] Ly, K.H., Carlbring, P. and Andersson, G. (2012) Behavioral Activation-Based Guided Self-Help Treatment Administered through a Smartphone Application: Study Protocol for a Randomized Controlled Trial. Trials, 13, 62. https://doi.org/10.1186/1745-6215-13-62

[40] Maroufizadeh, S., Zareiyan, A. and Sigari, N. (2014) Reliability and Validity of Persian Version of Perceived Stress Scale (PSS-10) in Adults with Asthma. Archives of Iranian Medicine, 17, 361-365.

[41] Endler, N.S. and Parker, J.D.A. (1990) Coping Inventory for Stressful Situations (CISS): Manual. Multi-Health Systems, Toronto.

[42] McWilliams, L.A., Cox, B.J. and Enns, M.W. (2003) Use of the Coping Inventory for Stressful Situations in a Clinically Depressed Sample: Factor Structure, Personality Correlates, and Prediction of Distress. Journal of Clinical Psychology, 59, 423-437. https://doi.org/10.1002/jclp.10080

[43] Shokri, O., Taghilou, S., Geravand, F., Paeizi, M., Moulaei Mohammad, A.B.D., Elahpour, M. and Akbari, H. (2008) Factor Structure and Psychometric Properties of the Farsi Version of the Coping Inventory for Stressful Situations (CISS). Advances in Cognitive Science, 10, 22-33. http://en.journals.sid.ir/ViewPaper.aspx?ID=140377

[44] Blumenthal, J.A., Babyak, M.A., Doraiswamy, P.M., Watkins, L., Hoffman, B.M., Barbour, K.A., Herman, S., Craighead, W.E., Brosse, A.L., Waugh, R., Hinderliter, 
A. and Sherwood, A. (2007) Exercise and Pharmacotherapy in the Treatment of Major Depressive Disorder. Psychosomatic Medicine, 69, 587-596. https://doi.org/10.1097/PSY.0b013e318148c19a

[45] Wipfli, B., Landers, D., Nagoshi, C. and Ringenbach, S. (2011) An Examination of Serotonin and Psychological Variables in the Relationship between Exercise and Mental Health. Scandinavian Journal of Medicine and Science in Sports, 21, 474481. https://doi.org/10.1111/j.1600-0838.2009.01049.x

[46] Craft, L.L. (2005) Exercise and Clinical Depression: Examining Two Psychological Mechanism. Psychology of Sport and Exercise, 6, 151-171.

[47] Rethorst, C.D., Sunderajan, P., Greer, T.L., Grannemann, B.D., Nakonezny, P.A., Carmody, T.J. and Trivedi, M.H. (2013) Does Exercise Improve Self-Reported Sleep Quality in Non-Remitted Major Depressive Disorder? Psychological Medicine, 43, 699-709. https://doi.org/10.1017/S0033291712001675

[48] Mead, G.E., Morley, W., Campbell, P., Greig, C.A., McMurdo, M. and Lawlor, D.A. (2009) Exercise for Depression. Mental Health and Physical Activity, 2, 95-96. https://doi.org/10.1016/j.mhpa.2009.06.001

[49] Bagley, S.L., Weaver, T.L. and Buchanan, T.W. (2011) Sex Differences in Physiological and Affective Responses to Stress in Remitted Depression. Physiology \& Behavior, 104, 180-186. https://doi.org/10.1016/j.physbeh.2011.03.004

[50] Juruena, M.F., Pariante, C.M., Papadopoulos, A.S., Poon, L., Lightman, S. and Cleare, A.J. (2009) Prednisolone Suppression Test in Depression: Prospective Study of the Role of HPA Axis Dysfunction in Treatment Resistance. British Journal of Psychiatry, 194, 342-349. https://doi.org/10.1192/bjp.bp.108.050278

[51] Bylsma, L.M., Taylor-Clift, A. and Rottenberg, J. (2011) Emotional Reactivity to Daily Events in Major and Minor Depression. Journal of Abnormal Psychology, 120, 155-167. https://doi.org/10.1037/a0021662

[52] Zschucke, E., Renneberg, B., Dimeo, F., Wüstenberg, T. and Ströhle, A. (2015) The Stress-Buffering Effect of Acute Exercise: Evidence for HPA Axis Negative Feedback. Psychoneuroendocrinology, 51, 414-425. https://doi.org/10.1016/j.psyneuen.2014.10.019

[53] Sothmann, M.S., Buckworth, J., Claytor, R.P., Cox, R.H., White-Welkley, J.E. and Dishman, R.K. (1996) Exercise Training and the Cross-Stressor Adaptation Hypothesis. Exercise and Sport Sciences Reviews, 24, 267-287.

https://doi.org/10.1249/00003677-199600240-00011

[54] von Haaren, B., Haertel, S., Stumpp, J., Hey, S. and Ebner-Priemer, U. (2015) Reduced Emotional Stress Reactivity to a Real-Life Academic Examination Stressor in Students Participating in a 20-Week Aerobic Exercise Training: A Randomised Controlled Trial Using Ambulatory Assessment. Psychology of Sport and Exercise, 20, 67-75.

[55] Puterman, E., O’Donovan, A., Adler, N.E., Tomiyama, J., Kemeny, M., Wolkowitz, O.M. and Epel, E. (2011) Physical Activity Moderates Effects of Stressor Induced Rumination on Cortisol Reactivity. Psychosomatic Medicine, 73, 604-611. https://doi.org/10.1097/PSY.0b013e318229e1e0

[56] Nolen-Hoeksema, S. (1991) Responses to Depression and Their Effects on the Duration of Depression Episodes. Journal of Abnormal Psychology, 100, 569-582. https://doi.org/10.1037/0021-843X.100.4.569

[57] Nolen-Hoeksema, S. (2001) Gender Differences in Depression. Current Directions in Psychological Science, 10, 173-176. https://doi.org/10.1111/1467-8721.00142

[58] McGreevy, C.A., Bonanno, G.A. and D’Andrea, W. (2015) Variation in the Physiological Costs and Benefits of Rumination and Distraction: The Moderating Effect of 
Habitual Thought Suppression. Personality and Individual Differences, 85, 93-97.

[59] LeMoult, J. and Joormann, J. (2014) Depressive Rumination Alters Cortisol Decline in Major Depressive Disorder. Biological Psychology, 100, 50-55.

[60] Ivan Santini, Z., Koyanagi, A., Tyrovolas, S., Mason, C. and MariaHaro, J. (2015) The Association between Social Relationships and Depression: A Systematic Review. Journal of Affective Disorders, 175, 53-65.

https://doi.org/10.1016/j.jad.2014.12.049

[61] Divney, A.A., Sipsma, H., Gordon, D., Niccolai, L., Magriples, U. and Kershaw, T. (2012) Depression during Pregnancy among Young Couples: The Effect of Personal and Partner Experiences of Stressors and the Buffering Effects of Social Relationships. Journal of Pediatric \& Adolescent Gynecology, 25, 201-207. https://doi.org/10.1016/j.jpag.2012.02.003

[62] Weik, U., Maroof, P., Zoller, C. and Deinzer, R. (2010) Pre-Experience of Social Exclusion Suppresses Cortisol Response to Psychosocial Stress in Women but Not in Men. Hormones and Behavior, 58, 891-897.

[63] Schmitz, N., Kruse, J. and Kugler, J. (2004) The Association between Physical Exercises and Health-Related Quality of Life in Subjects with Mental Disorders: Results from a Cross-Sectional Survey. Preventive Medicine, 39, 1200-1207.

[64] Sugiyama, T., Leslie, E., Giles-Corti, B. and Owen, N. (2008) Associations of Neighbourhood Greenness with Physical and Mental Health: Do Walking, Social Coherence and Local Social Interaction Explain the Relationships? Journal of Epidemiology and Community Health, 62, e9. https://doi.org/10.1136/jech.2007.064287

[65] Nagase, Y., Uchiyama, M., Kaneita, Y., Li, L., Kaji, T., Takahashi, S., Konno, M., Mishima, K., Nishikawa, T. and Ohida, T. (2009) Coping Strategies and Their Correlates with Depression in the Japanese General Population. Psychiatry Research, 168, 57-66. https://doi.org/10.1016/j.psychres.2008.03.024

[66] Fletcher, K., Parker, G.B. and Manicavasagar, V. (2013) Coping Profiles in Bipolar Disorder. Comprehensive Psychiatry, 54, 1177-1184.

https://doi.org/10.1016/j.comppsych.2013.05.011

Submit or recommend next manuscript to SCIRP and we will provide best service for you:

Accepting pre-submission inquiries through Email, Facebook, LinkedIn, Twitter, etc. A wide selection of journals (inclusive of 9 subjects, more than 200 journals)

Providing 24-hour high-quality service

User-friendly online submission system

Fair and swift peer-review system

Efficient typesetting and proofreading procedure

Display of the result of downloads and visits, as well as the number of cited articles

Maximum dissemination of your research work

Submit your manuscript at: http://papersubmission.scirp.org/

Or contact ojmp@scirp.org 